Post-print of: Materials Research Bulletin, volume 47, issue 12, December 2012, pages 44874490; http://dx.doi.org/10.1016/j.materresbull.2012.09.066

\title{
Bulk TiCxN1-x-15\%Co cermets obtained by direct spark plasma sintering of mechanochemical synthesized powders
}

Amparo Borrell (a), María Dolores Salvador (a), Victoria G. Rocha (b), Adolfo Fernández (b, c), Miguel Ángel Avilés (d), Francisco J. Gotor (d)

a Instituto de Tecnología de Materiales (ITM), Universidad Politécnica de Valencia, Camino de Vera s/n, 46022 Valencia, Spain

b ITMA MaterialsTechnology, Parque Tecnológico de Asturias, 33428 Llanera, Spain

c Centro de Investigación en Nanomateriales y Nanotecnología (CINN) [Consejo Superior de Investigaciones Científicas (CSIC)-Universidad de Oviedo (UO)-Principado de Asturias (PA)], Parque Tecnológico de Asturias, 33428 Llanera, Spain

d Instituto de Ciencia de Materiales de Sevilla (CSIC-US), Calle Américo Vespucio 49, 41092 Sevilla, Spain

\begin{abstract}
TiCxN1-x-15 wt.\%Co cermets were obtained by a mechanically induced self-sustaining reaction (MSR) and sintered by spark plasma sintering (SPS) technique at different temperatures $\left(1200-1400{ }^{\circ} \mathrm{C}\right)$ for $1 \mathrm{~min}$ in vacuum under a uniaxial load of $80 \mathrm{MPa}$. The evolution of microstructure and mechanical properties was investigated. SPS allowed high densification with limited grain growth at a relatively low temperature. Material sintered at $1300{ }^{\circ} \mathrm{C}$ showed a good combination of mechanical properties with Vickers hardness of $17.1 \pm$ $0.5 \mathrm{GPa}$, fracture toughness of $5.51 \pm 0.29 \mathrm{MPa} \mathrm{m} 1 / 2$ and bending strength of $904 \pm 12 \mathrm{MPa}$. Lower sintering temperature resulted in a decrease in bending strength due to poor cohesion between the ceramic and binder phases. An increase in sintering temperature would allow tailoring the cermet microstructure and, therefore, adjusting the Vickers hardness/fracture toughness relation.
\end{abstract}

\section{Keywords}

A. Carbides;A. Composites;D. Mechanical properties;D. Microstructure

\section{Introduction}

Ceramic-metal composites combining a hard ceramic phase and a binding metallic component are commonly known as "cermets". Modern cermets are normally based on titanium carbonitride, $\mathrm{Ti}(\mathrm{C}, \mathrm{N})$. Various carbides, nitrides as well as metal binders are used as raw 
materials for preparing $\mathrm{Ti}(\mathrm{C}, \mathrm{N})$-based cermets. These systems exhibit a complex microstructure according to the type of binary carbide used [1]. They have been employed since decades in different engineering applications such as cutting tools or wear resistant parts [2] and [3].

A key aspect to achieve high mechanical performance is to control the ceramic-metal bond during sintering [4]. For that reason, a number of additives such as WC and Mo2C are currently used in this process [5]. Moreover, the selection of suitable raw materials and adequate synthesis methods are essential to obtain high quality cermet powders, but also the correct choice of the sintering method is crucial to obtain composites with improved properties through microstructure control.

Recently, the mechanochemical process denoted as a mechanically induced self-sustaining reaction (MSR) has been successfully employed in the accurate synthesis of complex carbonitride phases. This process has allowed the synthesis of powdered cermets in a short time with nanometric characteristics, good stoichiometric control and low energetic cost [6]. Furthermore, non-conventional fast sintering technique, spark plasma sintering (SPS), has been proved to be a promising option for producing completely dense materials [7]. This technique can work at heating rates as large as hundreds of degrees per minute, combining high pressure and temperature in a short time [8]. These features allow the achievement of microstructures unattainable by other sintering methods and, therefore, mechanical properties superior to those obtained using conventional techniques. Thus, the improvement in cermet properties can be pursued following two approaches, formulation of new compositions and/or adjustment of microstructure features.

The aim of this work is to report the examination of the microstructure and mechanical properties of TiCN-15\%Co cermets first synthesized by MRS and, subsequently, sintered through SPS technique at different temperatures $\left(1200-1400{ }^{\circ} \mathrm{C}\right)$. The possibility of obtaining fully dense cermets at very low temperature is studied. The mechanical properties, such as bending strength, Vickers hardness and fracture toughness were investigated.

\section{Experimental}

Powdered cermets with a starting nominal composition of 85 wt.\%TiC0.5N0.5 and 15 wt.\%Co were synthesized by MSR from elemental powder mixtures of Ti (99\% in purity, <325 mesh, Strem Chemicals), graphite ( $<270$ mesh, Fe $\leq 0.4 \%$, Merck) and Co ( $99.9 \%$ in purity, $<100$ mesh, Sigma) in a nitrogen atmosphere ( $\mathrm{H} 2 \mathrm{O}$ and $\mathrm{O} 2 \leq 3 \mathrm{ppm}$, Air Liquide). This method takes advantage of the strong exothermic character of the titanium carbonitride formation from the elements to promote self-propagating reactions during milling. As this synthesis process is carried out from elemental components, the control of the powder composition can be easily accomplished.

Fifteen tempered steel balls $(\mathrm{d}=20 \mathrm{~mm}, \mathrm{~m}=32.6 \mathrm{~g})$ and $46.5 \mathrm{~g}$ of the elemental Ti/C/Co powder mixture were placed in a $300 \mathrm{ml}$ tempered steel vial (67 HRC) and milled under 6 atm of N2 using a modified planetary ball mill (Planetary Mill Pulverisette 4, Fritsch). The powderto-ball mass ratio (PBR) was $\sim 1 / 10.5$, and a spinning rate of $400 \mathrm{rpm}$ for both the rotation of the supporting disc and the superimposed rotation in the direction opposite to the vial was 
employed. The planetary mill allowed for operation at a constant gas pressure and the detection of self-propagating reactions during milling [6]. After $42 \mathrm{~min}$ of treatment in the planetary mill, the ignition of the self-propagating reaction associated with the formation of the carbonitride ceramic phase was observed. The milling continued for $30 \mathrm{~min}$ after ignition to ensure the completion of the reaction and the homogenization of the powdered cermet.

Powdered cermets were sintered using an SPS apparatus HP D25/1 (FCT Systeme GmbH, Rauenstein, Germany) at temperatures from 1200 to $1400{ }^{\circ} \mathrm{C}$ and $80 \mathrm{MPa}$ of pressure. In each test, $5 \mathrm{~g}$ of material were used, which were introduced into a $20 \mathrm{~mm}$ diameter graphite die. The tests were carried out under vacuum at a heating rate of $100{ }^{\circ} \mathrm{C} \mathrm{min}-1$ with a $1 \mathrm{~min}$ dwelling time at the maximum temperature. The density was measured by the Archimedes method (ISO-3369). Relative densities were estimated in accordance with the real density of the powder measured by Helium picnometry $(5.18 \mathrm{~g} \mathrm{~cm}-3)$.

Sintered cermets were longitudinally cut in half cylinders with a diamond saw and polished (Struers, model RotoPol-31) with diamond to $1 \mu \mathrm{m}$ roughness. The Vickers hardness value, Hv, was determined using a conventional diamond pyramid indenter with a load of $5 \mathrm{~N}$ for $10 \mathrm{~s}$ (Buehler, model Micromet 5103) and using the standard specification ASTM E92-72. The indentation fracture toughness value, KIC[9], was obtained by the method of Niihara et al. [10] from $294 \mathrm{~N}$ Vickers indentations that created Palmqvist cracks. The bending strength was measured at room temperature in the universal machine Instron (Model 856) with a crosshead displacement speed of $0.002 \mathrm{~mm} \mathrm{~s}-1$ using biaxial testing and the equations of Kirstein and Woolley [11], Vitman and Pukh [12], and the standard specification ASTM F394-78. The fracture surface sections of the sintered samples have been observed using a field emission gun scanning electron microscope (FESEM, HITACHI S-4800, SCSIE of the University of Valencia, Spain). The crystalline phases of the bulk ceramic composites were determined by X-ray diffraction (XRD, D8 Advance, Bruker, Germany). The measurements were performed in the $30-70^{\circ}$ range and the step size and time of reading were $0.02^{\circ}$ and $0.3 \mathrm{~s}$, respectively.

\section{Results and discussions}

Piston speed and displacement as a function of temperature for the sample sintered up to $1300{ }^{\circ} \mathrm{C}$ are shown in Fig. 1. In this cycle, the maximum pressure ( $80 \mathrm{MPa}$ ) was applied between 600 and $700{ }^{\circ} \mathrm{C}$, which produced the compaction of the powder. Once the maximum pressure had been reached it was held up to the each final temperature. After the first piston displacement, it was observed that sintering process started at $750{ }^{\circ} \mathrm{C}$ and the material was completely dense at temperatures as low as $1225^{\circ} \mathrm{C}$, approximately.

In this work, three final temperatures were chosen for sintering the cermets: a low temperature at which the material is not completely sintered $\left(1200{ }^{\circ} \mathrm{C}\right)$, a temperature at which densification is finished $\left(1300^{\circ} \mathrm{C}\right)$, and a higher temperature comparable with that used in pressureless process $\left(1400{ }^{\circ} \mathrm{C}\right)$ described in a previous work for cermets with similar composition [13]. 
The relative densities of the TiCxN1-x-15\%Co cermets sintered by SPS at 1200,1300 and 1400 ${ }^{\circ} \mathrm{C}$ were $98.5,>99.0$ and $>99.0 \%$ t.d., respectively. The high densification at relatively low temperatures is consequence of the optimum homogenization and distribution of the ceramic and binder phases obtained by MSR process and the sintering conditions applied during SPS. With this sintering technique, the material can be densified fairly quickly because of the high heating rate employed and the pressure applied during the process.

The XRD patterns of starting powder and samples sintered at 1200,1300 and $1400{ }^{\circ} \mathrm{C}$ are shown in Fig. 2, where peaks for TiCxN1-x and metallic binder phase are identified. The binder phase detected in the XRD diagrams was not elemental Co, but a TiCo intermetallic compound. This intermetallic was already observed in the powdered cermet and was obtained during the milling process. It has been previously shown that the formation of this intermetallic phase was triggered by the heat released during the self-propagating reaction involved in the carbonitride phase formation [6].

The presence of $\mathrm{Ti}$ in the binder decreased the amount of this metal available to form the carbonitride phase, and consequently, a composition richer in carbon than expected from the initial elemental mixture was observed. A TiC0.75N0.25 stoichiometry was estimated for the powdered cermet from the lattice parameter $(a=4.3036 \AA)$ assuming a Vegard's law behaviour for the TiCxN1-x solid solution in the TiC-TiN system.

Diffractograms in Fig. 2 are qualitatively similar, showing no phase transformation during SPS sintering, even at the highest temperature. The broadening of XRD peaks is also similar, only slightly narrower peaks are observed at $1400{ }^{\circ} \mathrm{C}$, as a clear indication that SPS technique is capable of preserving the microstructure of the starting material limiting the particle growth.

Fig. 3 shows the SEM micrographs of the fracture surface of sintered cermets, where the evolution of the ceramic grain size in function of the maximum sintering temperature is observed. It was possible to obtain near full density with an average grain size similar to starting powder for the lowest sintering temperature tested $\left(1200{ }^{\circ} \mathrm{C}\right)$. In this case, only isolated grains with larger grain size were observed. As the sintering temperature was increased, the proportion of these coarse grains increased at the expense of the smaller ones, leading to a material with a bimodal microstructure. These microstructures are unattainable by using other sintering techniques such as pressureless sintering or hot pressing. In those cases, the characteristic longer cycles certainly promote grain growth at high temperature and microstructural design is limited. SPS process is a much more versatile technique. As it is possible to obtain dense material preserving the microstructure of the starting powdered material, the additional energy provided by further increase on sintering temperature is consumed in grain growth processes leading to microstructures showing mixture of submicrometric and micrometric grains or completely microstructured materials similar to those obtained by alternative techniques. Then, SPS sintering appears as a very powerful tool for microstructural design.

The results obtained for hardness, fracture toughness and bending strength are reported in Table 1. All samples, independently of the sintering temperature, showed good combination of mechanical properties. The best values of hardness and bending strength were reached for the TiCxN1-x-15\%Co cermet sintered at $1300{ }^{\circ} \mathrm{C}$, while maximum fracture toughness 
corresponded to sample prepared at $1400{ }^{\circ} \mathrm{C}$. The differences in mechanical properties are related to the evolution of the microstructures of the sample. As a general trend, in materials with similar densities, with increasing grain size the hardness decreases according to a HallPetch type relationship [14], but fracture toughness tends to increase. Also, it is known that the binder phase in cermets prevents the crack propagation by shielding the stress field in front of crack tip or by bridging the crack forming ligaments behind the crack tip [15].

Cermets sintered at $1200{ }^{\circ} \mathrm{C}$ and $1300{ }^{\circ} \mathrm{C}$ had higher proportion of submicrometric grains, $<1$ $\mu \mathrm{m}$, and consequently they showed the highest hardness values and moderate fracture toughness. Nevertheless, when both samples were compared, it could be seen that cermet prepared at $1200{ }^{\circ} \mathrm{C}$ had $30 \%$ lower fracture strength. This difference was attributed, firstly, to the residual porosity of the material sintered at the lowest temperature that acted as critical flaws and, therefore, a cermet with a lower strength was observed. Moreover, cohesion between the ceramic and binder phases also influences the mechanical strength of dense material. Metallic binder acts as a liquid sintering additive during densification and metal component is more amorphous when sintering temperature approaches the formation temperature of the transitory liquid phase. In Fig. 2, it can be observed that the XRD peak corresponding to the binder phase in the case of cermet sintered at $1200{ }^{\circ} \mathrm{C}$ is more defined suggesting a higher crystallinity, whereas after sintering at $1300{ }^{\circ} \mathrm{C}$ or $1400{ }^{\circ} \mathrm{C}$ the peaks are wider appearing as a shoulder of the more intense TiCN peak. It is possible that at $1200{ }^{\circ} \mathrm{C}$, the formation of a liquid phase was not promoted reducing the interface bonding strength.

Cermet sintered at $1400{ }^{\circ} \mathrm{C}$ with average grain size around 4-5 $\mu \mathrm{m}$ showed higher hardness and similar fracture toughness when compared with cermets with the same composition, but obtained by a pressureless sintering procedure [13]. Moreover, processing times were dramatically reduced. Furthermore, material microstructure can be tailored by modifying the sintering parameters.

On the other hand, the values obtained in this work are in the range of those reported for $\mathrm{Ti}(\mathrm{C}$, N) cermets sintered by SPS, but with a much more complex composition adjusted for improved wettability and sinterability [16], [17] and [18].

In summary, for such TiCxN1-x-15\%Co cermet the optimum sintering temperature is around $1300{ }^{\circ} \mathrm{C}$. At this temperature it is possible to achieve its complete densification thanks to the binder phase. Lower temperature does not allow for complete sintering and higher temperature results in excessive grain growth. Particularly noteworthy is the high value of bending strength obtained at a sintering temperature as low as $1300{ }^{\circ} \mathrm{C}$ and for a cermet composed simply of a ceramic phase and a metallic phase. This was possible because MSR synthesis method is able to produce materials with unusually high chemical and microstructural homogeneities and with a large number of defects, which favours the use of milder sintering conditions. The accurate control of material composition by MSR process and microstructural features by SPS sintering opens new strategies for ceramic-metal composites design.

\section{Conclusions}


Titanium carbonitride powders with 15 wt.\%Co binder phase synthesized by a MSR process were sintered by SPS technique at low temperatures and with a whole processing time lower than $15 \mathrm{~min}$. The superior mechanical properties observed in these cermets were the consequence of a homogeneous chemical composition and microstructure developed during sintering. The cermet sintered at $1300{ }^{\circ} \mathrm{C}$ achieved high density $\sim 99 \%$ with excellent mechanical properties, especially Vickers hardness and bending strength (the average value were $17.1 \mathrm{GPa}$ and $904 \mathrm{MPa}$, respectively).

\section{Acknowledgements}

This work was supported by the Spanish Government under grant (MAT2011-22981), which is financed in part by the European Regional Development Fund of 2007-2013. A. Borrell acknowledges the Spanish Ministry of Science and Innovation for her "Juan de la Cierva" contract (JCl-2011-10498). 


\section{References}

[1]S.Y. Ahn, S.W. Kim, S. Kang

J. Am. Ceram. Soc., 84 (2001), pp. 843-849

[2]S. Cardinal, A. Malchere, V. Garnier, G. Fantozzi

Int. J. Refract. Met. Hard Mater., 27 (2009), pp. 521-530

[3]J. Pirso, M. Viljus, S. Letunovits

Wear, 260 (2006), pp. 815-824

[4]V.R. Dizaji, M. Rahmani, M.F. Sani, Z. Nemati, J. Akbari

Int. J. Mach. Tools Manuf., 47 (2007), pp. 768-772

[5] J.K. Park, S.T. Park

Int. J. Refract. Met. Hard Mater., 17 (1999), pp. 295-298

[6] J.M. Córdoba, M.J. Sayagüés, M.D. Alcalá, F.J. Gotor

J. Eur. Ceram. Soc., 28 (2008), pp. 2085-2098

[7]R.G. Joanna, Z. Antonios

Mater.Sci. Eng. A, 287 (2000), pp. 171-177

[8]Y. Wang, Z. Fu

Mater. Sci. Eng. B, 90 (2002), pp. 34-37

[9]G. Antis, P. Chantikul, B. Lawn, D. Marshall

J. Am. Ceram. Soc., 64 (1981), pp. 533-538

[10]K. Niihara, R. Morena, D.P.H. Hasselman

J. Mater. Sci. Lett., 1 (1982), pp. 13-16

[11]A.F. Kirstein, R.M. Woolley

J. Res. Natl. Bur. Stand. C, 71 (1967), pp. 1-10

[12]F.F. Vitman, V.P. Pukh

Zavod Lab., 29 (1963), pp. 863-867

[13]J.M. Córdoba, J.C. Sánchez-López, M.A. Avilés, M.D. Alcalá, F.J. Gotor 
J. Eur. Ceram. Soc., 29 (2009), pp. 1173-1182

[14]S. Bolognini, G. Feusier, D. Mari, T. Viatte, W. Benoit Int. J. Refract. Met. Hard Mater., 16 (1998), pp. 257-268

[15]L.S. Sigl, H.F. Fischmeister

Acta Metall., 36 (1988), pp. 887-897

[16]Y. Zheng, S. Wang, M. You, H. Tana, W. Xiong

Mater. Chem. Phys., 92 (2005), pp. 64-70

[17]M. Alvarez, J.M. Sánchez

Int. J. Refract. Met. Hard Mater., 25 (2007), pp. 107-118

[18]J.M. Sánchez, M. Alvarez, N. Rodriguez, M. Aristizabal

Mater.Sci. Eng. A, 500 (2009), pp. 225-232 
Figure captions

Figure 1.Piston speed and displacement during spark plasma sintering of TiCxN1-x-15\%Co cermet at $1300^{\circ} \mathrm{C}$.

Figure 2.X-ray diffractograms of the TiCxN1-x-15\%Co powdered material and after sintering at $1200{ }^{\circ} \mathrm{C}, 1300^{\circ} \mathrm{C}$ and $1400^{\circ} \mathrm{C}$ by SPS

Figure 3.FESEM micrographs of TiCxN1-x-15\%Co cermets sintered by SPS at (a) $1200{ }^{\circ} \mathrm{C}$, (b) $1300^{\circ} \mathrm{C}$ and (c) $1400{ }^{\circ} \mathrm{C}$. 
Table 1

Table 1.Mechanical properties of $\operatorname{TiC}_{x} \mathrm{~N}_{1-x}-15 \%$ Co cermets sintered by SPS at different temperatures.

\begin{tabular}{|l|l|l|l||}
\hline $\begin{array}{l}\text { Sinteringtemperature } \\
\left(\begin{array}{l} \\
\end{array}\right.\end{array}$ & $\begin{array}{l}\text { Vickershardness } \\
(\mathbf{G P a})\end{array}$ & $\begin{array}{l}\text { Fracture } \\
\text { toughness } \\
\left(\mathbf{M P a} \mathbf{~ m}^{\mathbf{1} / \mathbf{2}}\right)\end{array}$ & $\begin{array}{l}\text { Bendingstrength } \\
(\mathbf{M P a})\end{array}$ \\
\hline 1200 & $16.9 \pm 0.4$ & $5.67 \pm 0.65$ & $622 \pm 19$ \\
\hline 1300 & $17.1 \pm 0.5$ & $5.51 \pm 0.29$ & $904 \pm 12$ \\
\hline 1400 & $15.2 \pm 0.5$ & $7.25 \pm 0.72$ & $802 \pm 15$ \\
\hline
\end{tabular}


Figure 1

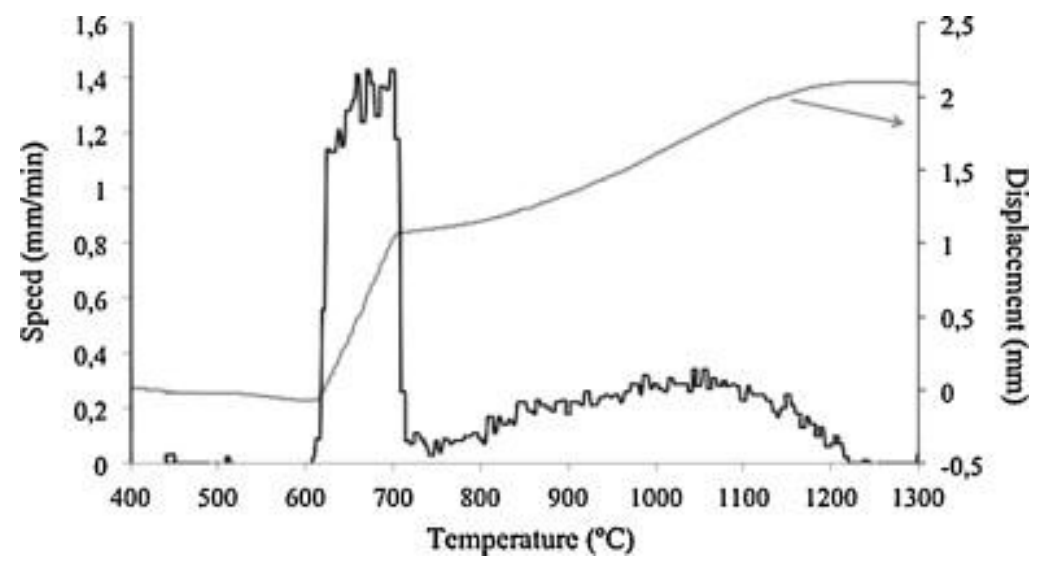


Figure 2

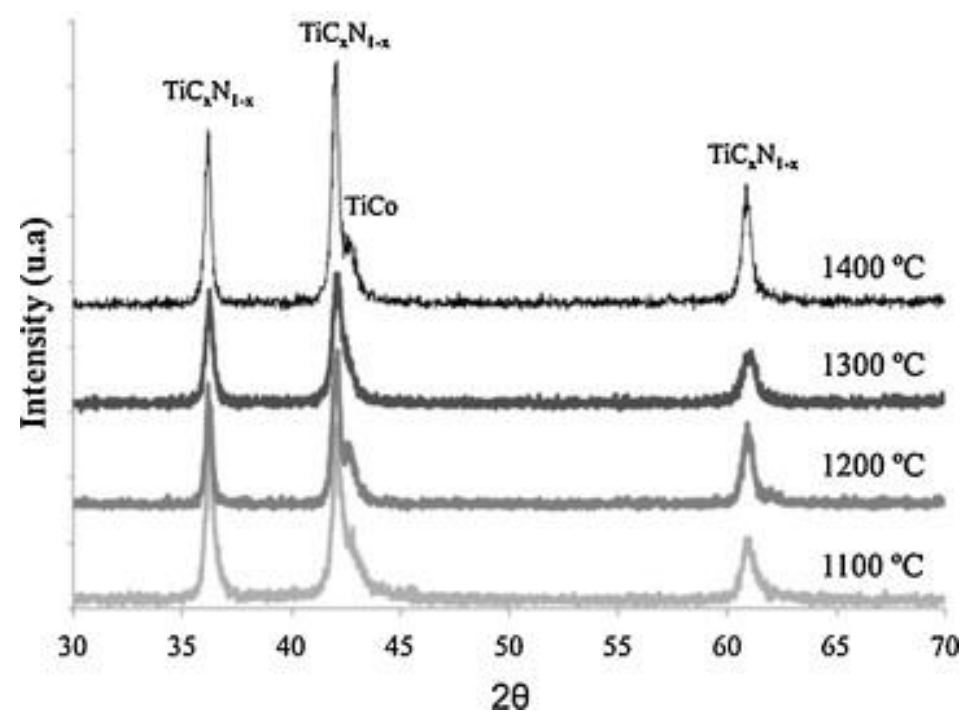


Figure 3
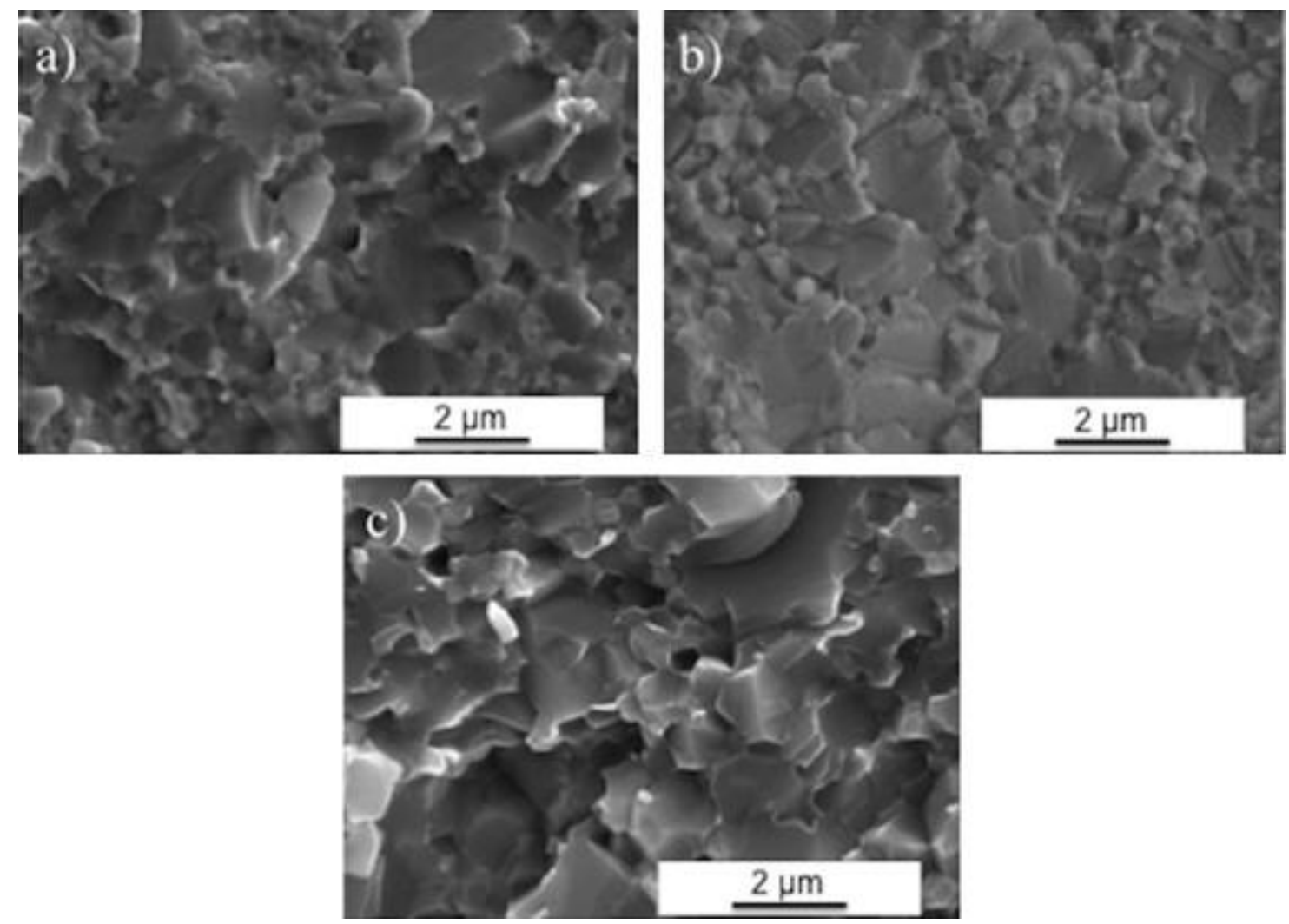